\title{
To Optimize the Process Parameters for the Improvement of Material Removal Rate and Surface Roughness using Cryogenic Treated and Untreated Wire in Wire Electrical Discharge Machining of Titanium Material
}

\author{
Utkarsh S Agrawal \\ PG student, mechanical department u.v.p.c.e, ganpat university, mahesana \\ Prof. U. J. Patel \\ Professor, mechanical department u.v.p.c.e, ganpat university, mahesana
}

\begin{abstract}
WEDM is popular and specialized in machining conductive metals of any hardness or that are difficult or impossible to cut with traditional methods into general, complex shapes, contours or fragile geometries. This project work focuses on finding out the effect of input parameters on output parameters in Wire-EDM for machining of Titanium. The input process parameters that are taken into consideration are wire feed rate, Pulse on time, Pulse off time, Peak current, Servo voltage and wires. Output parameters are Material removal rate (MRR) and Surface roughness (SR) is measured. Also different wire materials like Hard Brass wire and Cryogenic Treated Hard Brass wires are used in this experiment. For design of experiment Taguchi methodology of L27 orthogonal array is used. ANOVA is used for finding the percentage contribution of each parameter and found that MRR rises with rise in pulse on time and cryogenic treated wire for $4 \mathrm{hrs}$ gives more MRR compared to the cryogenic treated wire for $2 \mathrm{hrs}$. For SR it is determined that, SR rises with rise in peak current and servo voltage and cryogenic treated wire for $2 \mathrm{hrs}$ gives more SR compared to the nontreated wire and cryogenic treated wire for $4 \mathrm{hrs}$.
\end{abstract}

Keywords - WEDM, Titanium material, cryogenic treatment, Material removal rate, surface roughness, Taguchi approach, ANOVA.

\section{INTRODUCTION}

Wire electrical discharge machining (WEDM) is a widely used to manufacture components with intricate shapes and profiles. In Wire-EDM the material erodes from the job by means of a discrete runs of discharge that occur among the job and wire divided by a dielectric fluid. At present, WEDM is a widespread technique used in industry for high precision machining of all types of conductive materials. The WEDM process parameters influences the quality of processing, cutting or drilling in wire- EDM, and strength of the wire in wire-EDM can be achieved by a process termed as cryogenic treatment. In this after the treatment, there is change in the micro structure of the wire and cryogenic treatment is also wear and corrosion resistance, thus we are applying this cryogenic process in our work.

LITERATURE REVIEW-D.Sudhakara et al. introduced the promotion of the wire cut EDM machining factors for the roughness of the surface, $0.25 \mathrm{~mm}$ diameter wire is used for machining the material named as VANADIS $4 \mathrm{e}$, L27 orthogonal array was designed by the Taguchi method for performing experiments, $\mathrm{S} / \mathrm{N}$ ratio was applied for finding out the rank of each parameter on surface roughness and ANOVA was used for finding the percentage involvement of each factors on response[3]. S V Subrahmanyam et al. investigated to optimize the effects of eight input process parameters on Surface Finish during the machining of EN-31 using Taguchi L36 orthogonal array and with the help of ANOVA, S/N ratio and Math model the optimal input parameter combination for the Surface Finish on the WEDM machined arrived and said that it will be useful for the people who do not have much idea of WEDM[4]. S Sivakiran et al. attempted to study the influence of various machining parameters Pulse on, Pulse off, Bed speed and Current on metal removal Rate (MRR). The relationship between control parameters and Output parameter (MRR) is developed by means of linear regression. Taguchi's L16 (4*4) Orthogonal Array (OA) designs have been used on EN-31 tool steel to achieve maximum MRR[1]. U.Esme et al. studied that two of the techniques were applied as neural network and design of factorial in the prediction of surface roughness of the work piece taken as AISI 43-40 
steel, ANOVA technique used for finding the significant factor and the level of factors and variation of input factors to output were modelled mathematically through nonlinear regression method and resulted that rising the factors as wire feed, pulse duration and open circuit voltage raises roughness of surface while rising in flushing pressure reduces surface roughness[13]. Navjot Singh et al. investigated cryogenically treated zinc coated diffused brass wire and cryogenically treated plain brass wire have been used as cutting tool, AISI D3 die steel has been taken work piece. Taguchi's L9 orthogonal array has been used for design of experiments. The process performance is measured in terms of optimization of material removal rate and found that the cryogenically treated zinc coated diffused brass wire gives good material removal rate as compare to cryogenically treated plain brass wire[7]. Jatinder Kapoor et al. studied the effect of Cryogenic treated brass wire electrode on the surface of an EN-31 steel machined by WEDM. Full factorial experimental design strategy is used in the experimentation. ANOVA results indicated that all the process parameters have significant effect on SR. Surface roughness is improved with cryogenic treated brass wire electrode[8].

\section{DESIGN OF EXPERIMENTS}

Increasing productivity and improving quality are important goal in any business. The method for determining how to increase productivity and improving quality are evolving. The design of experiments (DOE) is an efficient procedure for planning experiments so that the obtained data can be analyzed to yield valid and objective conclusions. DOE begins with determining the objectives of an experiment and selecting the process factors for the study.

\section{A. Taguchi Technique}

Dr. Taguchi has developed a method predicated on "ORTHOGONAL ARRAY" experiments which gives much reduced "variance" for the experiment with "optimum settings" of control parameters. Thus with optimization of control parameters to obtain best results is achieved in the Taguchi Method. "Orthogonal Arrays" (OA) provide a set of well balanced (minimum) experiments and Dr. Taguchi's Signal-to-Noise ratios (S/N), which are log functions of desired output, accommodate as objective functions for optimization, avail in data analysis and presage of optimum results. Taguchi techniques concentrates on the actual application of the design plans somewhat than Advanced Statistics. As per the method of Taguchi, the $\mathrm{S} / \mathrm{N}$ ratio is the proportion between signal and noise where the signal signifies the appropriate value and undesirable value is signified by noise. The software Minitab supports to analyze the $\mathrm{S} / \mathrm{N}$ ratio on the basis of requested responses and make available table of analysis of variance and graph of the response to choose significant factor and to discover the involvement of percentage for each factor. Moreover the Minitab allots rank on the basis of values of delta; rank 1 for the maximum value delta, rank 2 for the second maximum and so forth. Ranks shows the specific importance of each parameter for the responses. Three levels for each control parameter will be used. Based on number of control parameter and their levels, L27 orthogonal array $(\mathrm{OA})$ was selected. Table 1 represents Control parameters with their level value.

Table 1 Control parameters with level value

\begin{tabular}{|c|c|c|c|c|}
\hline Serial No. & Machining Process Variables & Level 1 & Level 2 & Level 3 \\
\hline 1 & Wire Feed Rate $(\mathrm{m} / \mathrm{min})$ & 6 & 7 & 8 \\
\hline 2 & Pulse On Time $(\mu \mathrm{s})$ & 110 & 115 & 120 \\
\hline 3 & Pulse Off Time $(\mu \mathrm{s})$ & 50 & 55 & 60 \\
\hline 4 & Peak Current $($ Amp $)$ & 120 & 140 & 160 \\
\hline 5 & Servo Voltage $($ Volt $)$ & 15 & 20 & 25 \\
\hline 6 & Types Of Wire & A & B & C \\
\hline
\end{tabular}

\section{B. Cryogenic Treatment}

Cryogenic processing has a technique to make cool the tool or the work-piece in the elimination of the material of the procedures. Liquid Nitrogen which is liquefied to $-196^{\circ} \mathrm{C}$ through cooling, generally used as coolant. Liquid Nitrogen is non-corrosive, safe and non-flammable. In this work cryogenic treatment of three spool of hard brass wire of weight $1 \mathrm{~kg}$, one thermocol box and liquid nitrogen were taken. From the three spool of wire, two wire spool were treated by liquid nitrogen at $\left(-196^{\circ} \mathrm{C}\right)$ for $2 \mathrm{hrs}$ and $4 \mathrm{hrs}$ and one spool was untreated. Fig 1 shows the cryogenic treatment of the wire spools. 

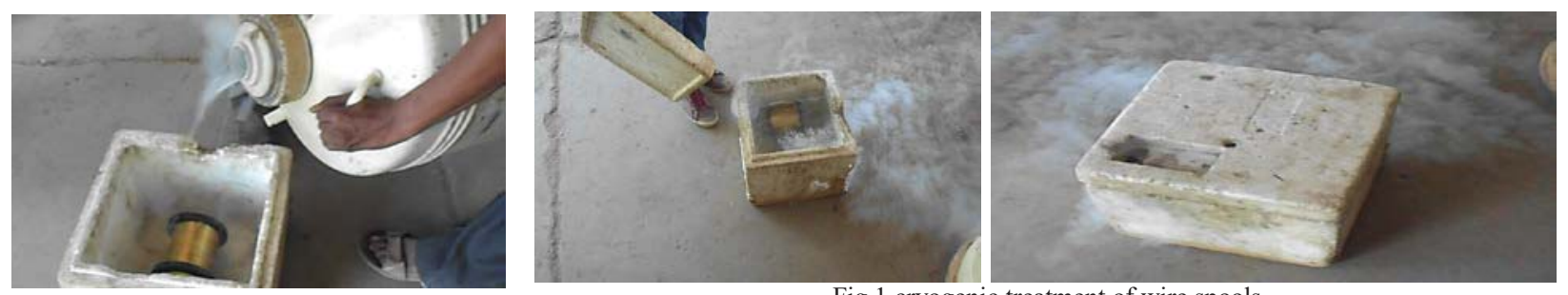

Fig 1 cryogenic treatment of wire spools

III. EXPERIMENT AND RESULT

For this work, the wire taken is Hard Brass Wire of $0.25 \mathrm{~mm}$ and the experiments performed is done in sprint-cut wire-EDM (ELEKTRA SPRINT-CUT 734) on Titanium material through changing the parameters of Processing. The size of the titanium material taken is $(250 \mathrm{~mm} \times 50 \mathrm{~mm} \times 6 \mathrm{~mm})$. The output parameters Material Removal Rate is found based on the volume method, the work piece to be machined is the volume of the material removal rate per minute. The equation-1 is used for finding out MRR values. The values of surface roughness of the finished products work pieces were calculated by Mitutoyo surface roughness tester, SJ-201 by means of a correct method. Table 2 shows the final measured results where in table A stands for non treated wire, B stands for cryo treated wire for $2 \mathrm{hrs}$ and $\mathrm{C}$ stands for cryo treated wire for $4 \mathrm{hrs}$.

MRR = Cutting Speed $(\mathrm{mm} / \mathrm{min}) *$ Thickness of $\mathbf{w} / \mathbf{p}(\mathrm{mm})$.

Table 2 final measured results

\begin{tabular}{|c|c|c|c|c|c|c|c|c|}
\hline $\begin{array}{c}\text { Serial } \\
\text { no }\end{array}$ & $\begin{array}{c}\text { Wire feed } \\
\text { rate } \\
(\mathrm{m} / \mathrm{min})\end{array}$ & $\begin{array}{c}\text { Pulse on } \\
\text { time } \\
(\mu \mathrm{s})\end{array}$ & $\begin{array}{c}\text { Pulse off } \\
\text { time } \\
(\mu \mathrm{s})\end{array}$ & $\begin{array}{c}\text { Peak } \\
\text { current } \\
(\text { Amp })\end{array}$ & $\begin{array}{c}\text { Servo } \\
\text { voltage } \\
(\mathrm{V})\end{array}$ & $\begin{array}{c}\text { Types of } \\
\text { wire }\end{array}$ & MRR & SR \\
\hline 1 & 6 & 110 & 50 & 120 & 15 & A & 21.30 & 2.17 \\
\hline 2 & 6 & 110 & 50 & 120 & 20 & B & 19.44 & 2.50 \\
\hline 3 & 6 & 110 & 50 & 120 & 25 & C & 18.24 & 2.12 \\
\hline 4 & 6 & 115 & 55 & 140 & 15 & A & 26.88 & 2.45 \\
\hline 5 & 6 & 115 & 55 & 140 & 20 & B & 25.32 & 2.58 \\
\hline 6 & 6 & 115 & 55 & 140 & 25 & C & 23.22 & 2.44 \\
\hline 7 & 6 & 120 & 60 & 160 & 15 & A & 26.88 & 3.08 \\
\hline 8 & 6 & 120 & 60 & 160 & 20 & B & 25.26 & 2.50 \\
\hline 9 & 6 & 120 & 60 & 160 & 25 & C & 23.88 & 2.65 \\
\hline 10 & 7 & 110 & 55 & 160 & 15 & B & 13.14 & 1.97 \\
\hline 11 & 7 & 110 & 55 & 160 & 20 & $\mathrm{C}$ & 12.06 & 2.39 \\
\hline 12 & 7 & 110 & 55 & 160 & 25 & A & 11.64 & 2.05 \\
\hline 13 & 7 & 115 & 60 & 120 & 15 & B & 20.88 & 2.36 \\
\hline 14 & 7 & 115 & 60 & 120 & 20 & C & 20.52 & 2.71 \\
\hline 15 & 7 & 115 & 60 & 120 & 25 & A & 19.98 & 2.37 \\
\hline 16 & 7 & 120 & 50 & 140 & 15 & B & 25.87 & 2.54 \\
\hline 17 & 7 & 120 & 50 & 140 & 20 & C & 40.03 & 2.85 \\
\hline 18 & 7 & 120 & 50 & 140 & 25 & A & 34.00 & 2.96 \\
\hline 19 & 8 & 110 & 60 & 140 & 15 & C & 12.24 & 2.47 \\
\hline 20 & 8 & 110 & 60 & 140 & 20 & A & 12.66 & 2.28 \\
\hline 21 & 8 & 110 & 60 & 140 & 25 & B & 11.22 & 2.14 \\
\hline 22 & 8 & 115 & 50 & 160 & 15 & C & 26.27 & 2.23 \\
\hline 23 & 8 & 115 & 50 & 160 & 20 & A & 26.04 & 2.58 \\
\hline 24 & 8 & 115 & 50 & 160 & 25 & B & 23.52 & 2.63 \\
\hline 25 & 8 & 120 & 55 & 120 & 15 & C & 33.54 & 3.07 \\
\hline 26 & 8 & 120 & 55 & 120 & 20 & A & 31.80 & 2.79 \\
\hline 27 & 8 & 120 & 55 & 120 & 25 & B & 34.20 & 2.89 \\
\hline
\end{tabular}


Signal-to-Noise Ratio (S/N Ratio)

The material removal rate is "larger the better" performance features and the surface roughness is "smaller the better", characteristics of performance and can be stated as. The S/N ratio for MRR and SR is measured by using equation 3 and 2. Table 3 and 4 displays the response table Wire for MRR and SR. The S/N ratio graph for input parameters versus MRR and SR is shown in fig 2 and 3.

$$
\begin{gathered}
S N i=-10 \log \left(\sum_{u=1}^{N i} \frac{y_{u}^{2}}{N_{i}}\right) . \\
S N i=-10 \log \left[\frac{1}{N_{i}} \sum_{u=1}^{N i} \frac{1}{y_{u}^{2}}\right] .
\end{gathered}
$$

Table $3 \mathrm{~S} / \mathrm{N}$ ratio for MRR

\begin{tabular}{|c|c|c|c|c|c|c|}
\hline Level & $\begin{array}{c}\text { Wire feed } \\
\text { rate }\end{array}$ & Pulse on time & $\begin{array}{c}\text { Pulse off } \\
\text { time }\end{array}$ & Peak current & Servo voltage & wire \\
\hline $\mathbf{1}$ & 27.30 & 23.08 & 28.14 & 27.49 & 26.79 & 26.96 \\
\hline $\mathbf{2}$ & 26.16 & 27.44 & 26.73 & 26.69 & 26.97 & 26.39 \\
\hline $\mathbf{3}$ & 26.70 & 29.65 & 25.29 & 25.98 & 26.41 & 26.81 \\
\hline Delta & 1.15 & 6.58 & 2.85 & 1.52 & 0.56 & 0.56 \\
\hline rank & 4 & 1 & 2 & 3 & 6 & 5 \\
\hline
\end{tabular}

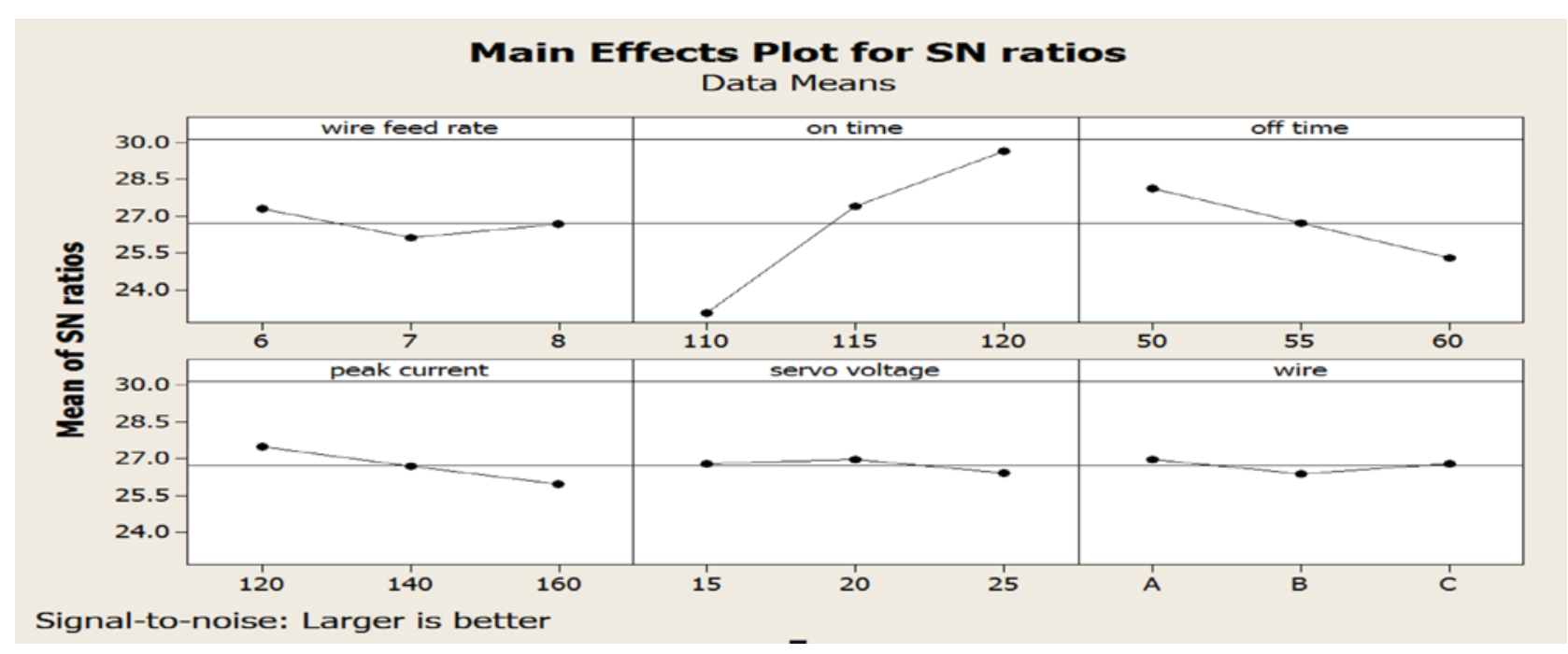

Fig 2 graph of input parameters versus MRR

Table $4 \mathrm{~S} / \mathrm{N}$ ratio for $\mathrm{SR}$

\begin{tabular}{|c|c|c|c|c|c|c|}
\hline Level & $\begin{array}{c}\text { Wire feed } \\
\text { rate }\end{array}$ & $\begin{array}{c}\text { Pulse on } \\
\text { time }\end{array}$ & $\begin{array}{c}\text { Pulse off } \\
\text { time }\end{array}$ & Peak current & $\begin{array}{c}\text { Servo } \\
\text { voltage }\end{array}$ & wire \\
\hline $\mathbf{1}$ & -7.908 & -6.948 & -7.937 & -8.078 & -7.810 & -7.971 \\
\hline $\mathbf{2}$ & -7.769 & -7.886 & -7.925 & -8.000 & -8.197 & -7.758 \\
\hline $\mathbf{3}$ & -8.121 & -8.965 & -7.936 & -7.721 & -7.791 & -8.070 \\
\hline
\end{tabular}




\begin{tabular}{|c|c|c|c|c|c|c|}
\hline Delta & 0.352 & 2.018 & 0.011 & 0.357 & 0.406 & 0.312 \\
\hline Rank & 4 & 1 & 6 & 3 & 2 & 5 \\
\hline
\end{tabular}

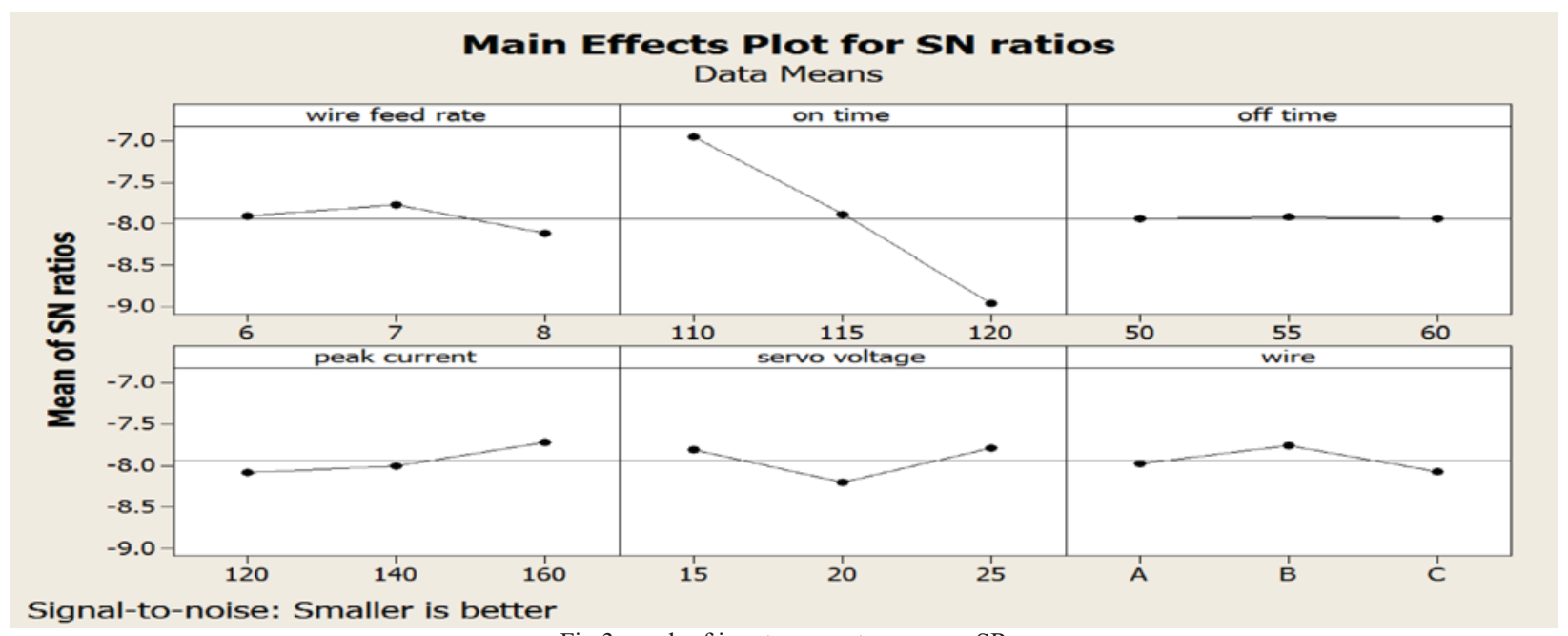

Fig 3 graph of input parameters versus SR

Analysis Of Variance (ANOVA)

ANOVA is an authentic statistical method to take the practical results. It can be used for estimating the percentage involvement of the different process factors selected for the functional characteristics. The study of ANOVA table for a specified investigation allows you to decide which parameters needs control and which does not need. ANOVA is to examine the parameters of the project and to specify which are the parameters that will considerably affect the output factors. The variance and sum of squares are measured in the investigation. A F-test value at a sureness level of $95 \%$ is taken for determining the major parameters that influence the process. Greater F- value specifiesthe variant of the factors of the process makes a large variation on performance. ANOVA investigation is performed in Minitab 16 software. If the value of $\mathrm{p}$ identified as possibility value which is smaller than 0.05 , displays that all factors are significant. The ANOVA table for material removal rate and surface roughness are displayed under, the percentage of each factor is found by using equation 4 displayed below.

$$
\%=\frac{\text { Seq SS }}{\text { Total Seq SS }} * 100
$$

Table 5 Analysis Of Variance for MRR

\begin{tabular}{|c|c|c|c|c|c|c|c|}
\hline Source & DF & Seq SS & Adj SS & Adj MS & F & P & \% \\
\hline $\begin{array}{c}\text { Wire feed } \\
\text { rate }\end{array}$ & 2 & 12.81 & 12.81 & 6.40 & 0.83 & 0.457 & $\mathbf{0 . 8 1}$ \\
\hline $\begin{array}{c}\text { Pulse on } \\
\text { time }\end{array}$ & 2 & 1150.91 & 1150.91 & 575.45 & 74.52 & 0.000 & $\mathbf{7 3 . 6 0}$ \\
\hline $\begin{array}{c}\text { Pulse off } \\
\text { time }\end{array}$ & 2 & 215.46 & 215.46 & 107.73 & 13.95 & 0.000 & $\mathbf{1 3 . 7 7}$ \\
\hline $\begin{array}{c}\text { Peak } \\
\text { current }\end{array}$ & 2 & 55.96 & 55.96 & 27.98 & 3.62 & 0.054 & $\mathbf{3 . 5 7}$ \\
\hline $\begin{array}{c}\text { Servo } \\
\text { voltage }\end{array}$ & 2 & 9.79 & 9.79 & 4.90 & 0.63 & 0.545 & $\mathbf{0 . 6 2}$ \\
\hline Wire & 2 & 10.67 & 10.67 & 5.33 & 0.69 & 0.518 & $\mathbf{0 . 6 8}$ \\
\hline Error & 14 & 108.11 & 108.11 & 7.72 & & & $\mathbf{6 . 9 5}$ \\
\hline
\end{tabular}




\begin{tabular}{|l|l|l|l|l|l|l|l|}
\hline Total & 26 & 1563.69 & & & & & $\mathbf{1 0 0}$ \\
\hline
\end{tabular}

\begin{tabular}{|c|c|c|c|c|c|c|c|}
\hline Source & DF & Seq SS & Adj SS & Adj MS & F & P & \% \\
\hline $\begin{array}{c}\text { Wire feed } \\
\text { rate }\end{array}$ & 2 & 0.04469 & 0.04469 & 0.02234 & 0.49 & 0.625 & $\mathbf{1 . 8 8}$ \\
\hline $\begin{array}{c}\text { Pulse on } \\
\text { time }\end{array}$ & 2 & 1.53502 & 1.53502 & 0.76751 & 16.70 & 0.000 & $\mathbf{6 4 . 7 6}$ \\
\hline $\begin{array}{c}\text { Pulse off } \\
\text { time }\end{array}$ & 2 & 0.00029 & 0.00029 & 0.00014 & 0.00 & 0.997 & $\mathbf{0 . 0 1}$ \\
\hline $\begin{array}{c}\text { Peak } \\
\text { current }\end{array}$ & 2 & 0.04740 & 0.04740 & 0.02370 & 0.52 & 0.608 & $\mathbf{2 . 0 0}$ \\
\hline $\begin{array}{c}\text { Servo } \\
\text { voltage }\end{array}$ & 2 & 0.05847 & 0.05847 & 0.02923 & 0.64 & 0.544 & $\mathbf{2 . 4 6}$ \\
\hline Wire & 2 & 0.04062 & 0.04062 & 0.02031 & 0.44 & 0.651 & $\mathbf{1 . 7 1}$ \\
\hline Error & 14 & 0.64351 & 0.64351 & 0.04597 & & & $\mathbf{2 7 . 1 8}$ \\
\hline Total & 26 & 2.37000 & & & & & $\mathbf{1 0 0}$ \\
\hline
\end{tabular}

\section{IV.CONCLUSION}

MRR rises with rise in pulse on time and is significant and comparative essential factor related to the other factors for MRR. This is because the discharge energy increases with pulse on time and the number of discharges within a given period becomes more. Wire feed rate shows minor effect on MRR and Wire C (cryogenic treated wire for 4hrs) gives more MRR compared to the wire B (cryogenic treated wire for $2 \mathrm{hrs}$ ).

On greater pulse off time, a smaller amount of quantity of sparks is passed for the period of processing, gives lesser MRR. Because of which minor holes are generated on the exterior gives minor SR, raising in servo voltage reduces the sparks through the wire-electrode gives lesser MRR.

For SR it is determined that, SR rises with rise in peak current and servo voltage, wire feed rate shows minor effect on SR. The purpose for raising of SR in peak current, is the quantity of energy for each spark rests on the value of the peak current, higher is the current value extra energy is released, results in greater SR. Here also pulse on time is significant and comparative essential factor related to the other factors for SR. Wire B (cryogenic treated wire for $2 \mathrm{hrs}$ ) gives more SR compared to the wire A (non-treated wire) and C (cryogenic treated wire for $4 \mathrm{hrs}$ ).

The percentage contribution of Wire feed rate is $0.81 \%$, Pulse on time is $73.60 \%$, Pulse off time is $13.77 \%$, Peak current is $3.57 \%$, Servo voltage is $0.62 \%$, wires is $0.68 \%$ and error is $6.95 \%$ for MRR.

The percentage contribution of Wire feed rate is $1.88 \%$, Pulse on time is $64.76 \%$, Pulse off time is $0.01 \%$, Peak current is $2.00 \%$, Servo voltage is $2.46 \%$, wires is $1.71 \%$ and error is $27.18 \%$ for SR.

\section{REFERENCES}

[1] S Sivakiran, C. Bhaskar Reddy, C. Eswara Reddy, "Effect Of Process Parameters On Mrr In Wire Electrical Discharge Machining Of En31 Steel", International Journal Of Engineering Research And Applications, vol. 2, issue 6, november- december 2012, pp.1221-1226.

[2] S V Subrahmanyam, M. M. M. Sarcar, "Evaluation Of Optimal Parameters For Machining With Wire Cut Edm Using Grey-Taguchi Method", International Journal Of Scientific And Research Publications, volume 3, issue 3, march 2013.

[3] D.Sudhakara, G.Prasanthi, "Application Of Taguchi Method For Determining Optimum SurfaceRoughness In Wire Electric Discharge Machining Of P/M Cold Worked Tool Steel (Vanadis-4e)", 12th Global Congress On Manufacturing And Management, Gcmm 2014 Elsevier, procedia engineering 97 ( 2014 ) $1565-1576$.

[4] S V Subrahmanyam, M. M. M. Sarcar, "Statistical Analysis Of Wire Electrical Discharge Machining On Surface Finish", International Journal Of Engineering Research \& Technology, vol. 2 issue 3, march - 2013.

[5] M. Durairaj, D. Sudharsun, N. Swamynathan, "Analysis Of Process Parameters In Wire Edm With Stainless Steel Using Single Objective Taguchi Method And Multi Objective Grey Relational Grade", International Conference On Design And Manufacturing, Icondm 2013 Elsevier, procedia engineering 64 ( 2013 ) 868 - 877. 
[6] Parveen Kr. Saini, Mukesh Verma, "Experimental Investigation Of Wire-Edm Process Parameters On MRR Of Ti-6al-4v Alloy", International Journal Of Innovative Technology And Exploring Engineering, volume-4, issue-5, october 2014.

[7] Navjot Singh, Parlad Kumar, Khushdeep Goyal, "Effect Of Two Different Cryogenic Treated Wires In Wire Electrical Discharge Machining Of Aisi D3 Die Steel”, Journal Of Mechanical Engineering, vol. Me 43, no. 2, december 2013.

[8] Jatinder Kapoor, Jaimal Singh Khamba And Sehijpal Singh, "Effects Of Cryogenic Treated Wire Electrode On The Surface Of An En-31 Steel Machined By Wedm", International Journal Of Surface Engineering \& Materials Technology, vol. 1 no. 1 july-dec. 2011.

[9] Domenico Umbrello, Fabrizio Micari , I.S. Jawahir, "The Effects Of Cryogenic Cooling On Surface Integrity In Hard Machining: A Comparison With Dry Machining", Cirp Annals - Manufacturing Technology Elsevier, 61 (2012) 103-106.

[10] Amoljit Singh Gill, Amit Thakur, Sanjeev Kumar, "Effect Of Deep Cryogenic Treatment On The Surface Roughness Of Ohns Die Steel After Wedm", International Journal Of Applied Engineering Research, issn 0973-4562 vol.7 no.11 (2012).

[11] Bijaya Bijeta Nayak, Siba Sankar Mahapatra, "Optimization Of Wedm Process Parameters Using Deep Cryo-Treated Inconel 718 As Work Material”, Engineering Science And Technology, An International Journal, Elsevier, 2015.

[12] Jaganathan P, Naveen Kumar T, Dr. R.Sivasubramanian, "Machining Parameters Optimization Of WEDM Process Using Taguchi Method",International Journal Of Scientific And Research Publications, Volume 2, Issue 12, December 2012.

[13] U. Esme, A. Sagbas And F. Kahraman, "Prediction Of Surface Roughness In Wire Electrical Discharge Machining Using Design Of ExperimentsAnd Neural Networks", Iranian Journal Of Science \& Technology, vol. 33, no. B3, pp 231-240. 